\title{
Detection of a pheomelanin-like pigment by EPR spectroscopy in the mycelium of Plenodomus biglobosus*
}

\author{
Jan Pukalski ${ }^{1}$, Natalia Marcol' ${ }^{1}$ Norbert Wolan², Przemysław Mieszko Płonka², \\ Przemysław Ryszka ${ }^{3}$, Tadeusz Kowalski ${ }^{4}$ and Dariusz Latowski1ه
}

'Department of Plant Physiology and Biochemistry, Faculty of Biochemistry, Biophysics and Biotechnology, Jagiellonian University, Kraków, Poland; 2Department of Biophysics, Faculty of Biochemistry, Biophysics and Biotechnology, Jagiellonian University, Kraków, Poland; 3 Institute of Environmental Sciences, Faculty of Biology, Jagiellonian University, Kraków, Poland; ${ }^{4}$ Department of Forest Ecosystem Protection, Faculty of Forestry, University of Agriculture, Kraków, Poland

\begin{abstract}
Melanin occurrence in Plenodomus biglobosus was investigated using the electron paramagnetic (spin) resonance (EPR, ESR) spectroscopy. The fungus was isolated from living and dead leaves of European ash (Fraxinus excelsior L.). Dark pigmentation of $P$. biglobosus mycelium in vitro, especially on the reverse side, was observed. The black coloration intensified with the age of the culture and inspired us to check if the analyzed fungus species synthesizes melanin. Melanin contains unpaired electrons, thus, EPR spectroscopy was applied as a specific technique to verify its presence in $P$. biglobosus. The EPR spectrum of the mycelium showed a very strong melanin signal, revealing pheomelanin-like features. Thus, the black pigment of $P$. biglobosus was clearly identified as melanin. However, no melanin was detected in the apparently dark culture medium even when zinc (II) acetate was added to increase the sensitivity of detection. Pheomelanin has many unusual biological functions but it is not commonly found in fungi. Detection of this type of melanin in $P$. biglobosus, which can be both endophytic or pathogenic, suggests a closer examination of the potential role of this melanin in the host-parasite interaction.
\end{abstract}

Key words: endophytes, ESR, Fraxinus, melanin, Leptosphaeria biglobosa, Phoma

Received: 21 May, 2020; revised: 13 June, 2020; accepted: 22 June, 2020; available on-line: 27 August, 2020

๑e-mail: dariusz.latowski@uj.edu.pl

*Presented at the XIVII Winter School of the Faculty of Biochemistry, Biophysics and Biotechnology of the Jagiellonian University "Molecules, Pathways, and Games", February 8-12, 2020, Zakopane, Poland.

Acknowledgements of Financial Support: This research was partially financed by the Polish National Science Centre under project no. 2016/21/B/NZ9/01226 and partially under the Jagiellonian University project no. BMN3/2017BMN4/2017.

Abbreviations: DHI, 5,6-dihydroxyindole; DHICA, 5,6-dihydroxyindole-2-carboxylic acid; DHN, dihydroxynaphthalene; DOPA, 3,4-dihydroxyphenylalanine; EPR, electron paramagnetic resonance (called also ESR, electron spin resonance); $M E$, malt extract

\section{INTRODUCTION}

Fungi constitute a separate Kingdom in Eukaryotes, and are a very diverse group of organisms occurring all over the world. Despite their ubiquity, fungi are still relatively poorly known regarding the production of biologically-active substances. On the other hand, they are potentially considered as the richest source of such substances (Pusztahelyi et al., 2015). In this paper we examine if the black color of a fungus isolated from leaves of European ash (Fraxinus excelsior L.) is determined by melanins. Ash leaf petioles play an important role in the development of the ascomycete fungus Hymenosyphus fraxineus (T. Kowalski) Baral et al. (anam. Chalara fraxinea T. Kowalski), which is a dangerous pathogen of ash, presumably introduced from East Asia (Kowalski, 2006; Baral et al., 2014; Gross et al., 2014). H. fraxineus causes an epidemic disease commonly known as ash dieback, spreading across Europe for about 20 years. It is a serious threat for European ash (Gross et al., 2014). After leaf infection, mycelium of $H$. fraxineus overgrows through the petioles to the ash branches and initiates dieback of the tree crown. In the following year, $H$. fraxineus can produce fruitbodies on infected leaves which fell onto the ground. These fruitbodies eject ascospores, which can cause new infections on other, so far symptomless ash trees.

In Poland, the fungal community living on both, the alive and dead petioles, has been studied for several years. In this context, competitive ability of various fungi towards the ash pathogen $H$. fraxineus is being investigated aiming at identification of potential antagonists against the ash dieback pathogen (Kowalski, unpublished). Among the fungal community obtained in these studies, several strongly pigmented slow growing isolates were found. The dark pigmentation of the colonies was observed both in monocultures and, even more pronounced, in dual cultures with $H$. fraxineus (unpublished data). Thus, we hypothesized that this pigmentation is caused by a melanin, which is possibly biologically active.

Melanins are ubiquitous biopolymers found in each group of organisms: Prokaryotes (Drewnowska et al., 2015; Bolognese et al., 2019), plants (Varga, 2016; Shoeva et al., 2020), animals and humans (Barek et al., 2018; Ali \& Naaz, 2018; Słominski et al., 2005b), slime molds (Płonka \& Rakoczy, 1997) and fungi (Dadachova \& Casadevall, 2008; Nosanchuk et al., 2015; Suwannarach et al., 2019). They may be synthesized via enzymatic reaction pathways or by spontaneous oxidative processes (Kaney \& Knox, 1980; Martin Gonzalez et al., 1997; Płonka \& Garbacka, 2006). Melanins may act as antioxidants (ROS scavengers) (de Cassia R. Goncalves \& Bonperio-Sponchiado, 2005; Wang et al., 2006), protective pigments against intense irradiation (Kollias et al., 1991; El-Bialy et al, 2019; Zadlo 2019), chelators for metals (Thaira et al., 2018; Zadlo \& Sarna, 2019) and toxins (Karlsson et al., 2009), ecologically and evolu- 
$\mathbf{A}$<smiles>CC1=C(O)C(=O)[C@@H](C)c2cc(C)[nH]c21</smiles>

B<smiles></smiles>

Figure 1. Mers characteristics for:

A - eumelanin (semiquinone radical), B - pheomelanin (semiquinonimine radical). ' $\because$ ' - free electron of radical molecule ( $\mathbf{A}$ - modified after Godechal \& Gallez, 2011; B - modified after Sealy et al., 1982b; Płonka \& Garbacka, 2006)

tionary important pigments supporting cryptic pigmentation (Kelley et al., 2016; Polo-Cavia \& Gomez-Mestre, 2017) and mimicry (Hines et al., 2017), as a virulence factor in various fungal species (Polak, 1990; Płonka \& Grabacka, 2006) or even as metabolites necessary for proper spore formation (Yu et al., 2015; Zhang et al., 2017). Physicochemical and biological properties of melanin, such as its color, are determined by the level of polymerization, and the structure of its mers (Fig. 1) that build a given melanin polymer (Micillo et al., 2016).

Melanins are divided into three main groups: eumelanins, pheomelanins and allomelanins. Eumelanins are dark (black, brown) colored pigments synthesized from tyrosine and/or phenylalanine during oxidation processes. An important stage of eumelanin synthesis is cyclization of DOPAquinone (derived from o-dihydroxyphenylalanine; DOPA) to leucodopachrome (Fig. 2A) and further to 5,6-dihydroxyindole (DHI) and/or 5,6-dihy-droxyindole-2-carboxylic acid (DHICA) (Land et al., 2004).

Pheomelanins are yellow-red pigments synthesized similarly to eumelanins at the early stage, but DOPAquinone is cysteinylated (Fig. 2B) before cyclization. Thus, pheomelanins are pigments containing sulphur in their molecular structure (Land et al., 2004).

Allomelanins are the most diverse group among melanins, and generally do not contain nitrogen (if they are not synthesized from tyrosine). Characteristic subgroups of allomelanins are DHN-(1,8-dihydroxynaphthalene)derived melanins and pyomelanins. Molecules specific for synthesis pathways of these subgroups are 1,8 DHN (Fig. 2C) and the homogentisate anion (Fig. 2D), respectively (Płonka \& Garbacka, 2006; Wang et al., 2015).

Melanin biosynthesis in fungal cells takes place in subcellular organelles called melanosomes (Eisenman \& Casadevall, 2012; Nosanchuk et al., 2015), analogous to the mammalian melanosomes where mammalian mel-

anogenesis occurs (Slominski et al., 2004; Eisenman \& Casadevall, 2012; Ali \& Naaz, 2018). The synthesized fungal melanins can be released to the extracellular space or they associate with cell walls, thus also affecting their structure and porosity (Fogarty \& Tobin, 1996; Eisenman \& Casadevall, 2012).

A characteristic property of melanins is paramagnetism caused by the presence of an unpaired electron in the semiquinone (Fig. 1A) or semiquinonimine (Fig. 1B) group (Sealy et al., 1982b, Godechal \& Gallez, 2011; Chikvaidze et al., 2014). Thus, melanins are unique pigments, which are stable radicals. As a stable free radical systems, melanins can be analyzed with electron paramagnetic (spin) resonance (EPR, ESR) spectroscopy, which is considered to be one of the most selective and sensitive analytical methods of spectroscopy for these pigments studies. EPR spectroscopy is a method for analysis of materials containing unpaired electron systems. The presence of stable semiquinone or semiquinonimine radicals makes melanin measurements independent on the use of additional, exogenous spin labels. Furthermore, EPR spectroscopy excels over UV-Vis and other methods due to much greater specificity.

Spectroscopy not only allows for detection of melanin in a biological system but also for its qualitative analysis - melanin systems made of benzothiazine are characterized by the spectrum containing hyperfine structure, whereas melanins produced only of tyrosine (without participation of the sulfur-containing components) are characterized by a simple spectrum (Sealy et al., 1982b). Additional advantages of EPR spectroscopy are non-invasiveness - the sample does not need to be processed before testing, and non-destructiveness - the sample is not damaged under measurement conditions (Chikvaidze et al., 2014). Therefore, EPR spectroscopy was applied as a sensitive and highly specific method to test the hypothesis that the black color of the fungus from ash leaves is determined by melanins, and if so, to determine which kind of melanin is produced by the mycelium.

\section{MATERIALS AND METHODS}

Fungal culture. Plenodomus biglobosus was isolated both from living symptomless leaf's petioles and from dead previous year petioles of the European ash collected from litter. They were not infected by $H$. fraxineus. The petioles were surface-sterilized by first soaking for $1 \mathrm{~min}$ in $96 \%$ ethanol, then for $5 \mathrm{~min}$ in a solution of sodium hypochlorite (approx. 4\% available chlorine) and finally for $30 \mathrm{~s}$ in $96 \%$ ethanol. After drying in layers of blotting paper, twelve pieces from each petiole were cut out<smiles>CCCC[C@H](S)[C@H](C)C(=O)O</smiles>

C<smiles>Oc1cccc2cccc(O)c12</smiles><smiles>O=C([O-])Cc1cc(O)ccc1O</smiles>

Figure 2. Characteristic stages of synthesis of:

A - eumelanin (cyclization of dopaquinone to leucodopachrome), B - pheomelanin (cysteinylation of dopaquinone to cysteinylDOPA directly or via glutathione (GSH)); characteristic molecules in syntheses of: C - DHN-melanins (1,8 DHN, 1,8- dihydroxynaphthalene), D pyomelanins (homogentisate anion). Modified after Płonka \& Garbacka, 2006 

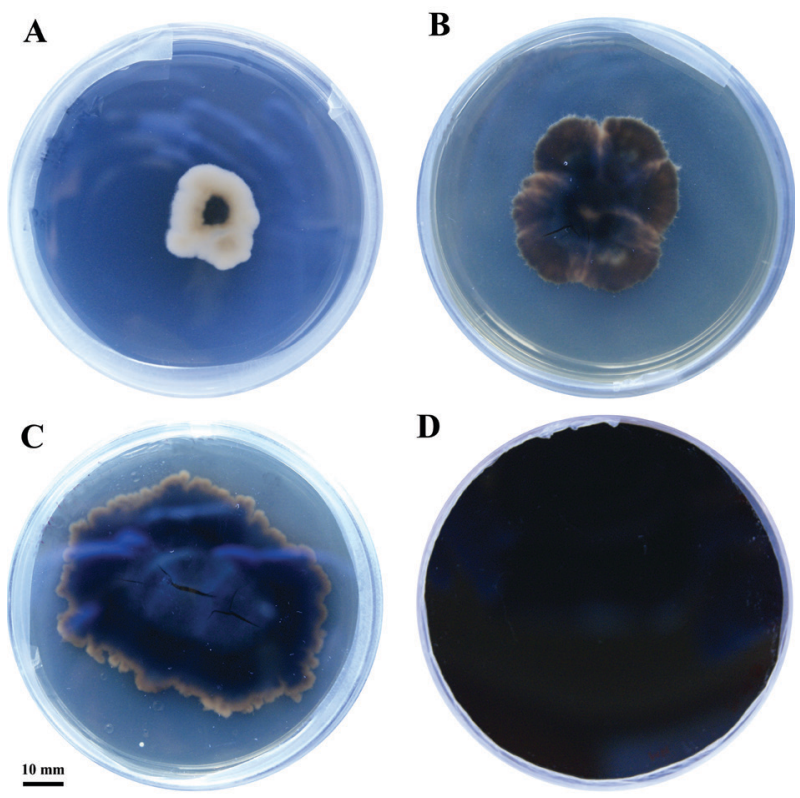

Figure 3. Images of fungal colonies documented after: A - 2 weeks, B - 3 weeks, C - 6 weeks, D - 3 months

and placed on the surface of malt extract agar (MEA; $20 \mathrm{~g} \mathrm{l}^{-1}$ malt extract (Difco; Sparks, MD, USA), $15 \mathrm{~g} \mathrm{l}^{-1}$ agar Difco supplemented with $100 \mathrm{mg} \mathrm{l}^{-1}$ streptomycin sulphate) in Petri dishes (diameter $9 \mathrm{~cm}$ ). Among the many isolated fungal taxa, one, getting black during in vitro culture, was selected to further studies. It was isolated on 29 August 2018 from a living symptomless petiole sampled from young European ash growing in the Myślenice Forest District (Malopolska, Poland). In dual cultures, both species, $P$. biglobosus and $H$. fraxineus, showed growth inhibition towards their counterpartner, and between them an inhibition zone was formed wider than $5 \mathrm{~mm}$. The examined strain is deposited at the Department of Forest Ecosystem Protection at Agriculture University in Kraków (HMC 21532).

The selected strain was cultivated at $20^{\circ} \mathrm{C}$ in the dark on the malt extract medium (ME; $20 \mathrm{~g} / 1$ (BIO-CORP)) as liquid, and on $1.5 \%$ agar as solid cultures. The change of mycelium color during growth was photodocumented after 2, 3, 6 weeks and 3 months (Fig. 3). DNA from the mycelium was isolated using DNA Mini Kit (Syngen Biotech, Wrocław, Poland) and amplified using the following primers: ITS1F (5'-CT'T GGT CAT TTA GAG GAA GTA A-3') (Gardes \& Bruns, 1993) and LR6 (5'CGC CAG TTC TGC TTA CC-3') (Vilgalys \& Hester, 1990).

Identification of the fungus was based on internal transcribed spacer (ITS) sequence which was verified using both, GenBank (https://www.ncbi.nlm.nih.gov/, accessed 24.04.2020, Altschul et al., 1990) and UNITE (https://unite.ut.ee/, accessed 24.04.2020, Nilsson et al., 2019) databases.

\section{EPR studies}

Analysis of mycelium and synthetic melanins. The mycelium with agar from a solid culture was resected with a lancet and packed densely into an EPR glass tube (inner diameter $4 \mathrm{~mm}$, length $2.5 \mathrm{~cm}$ ) whereupon the glass tube was frozen in liquid nitrogen to form an icicle. The sample was subsequently transferred to a quartz finger Dewar filled with liquid nitrogen.
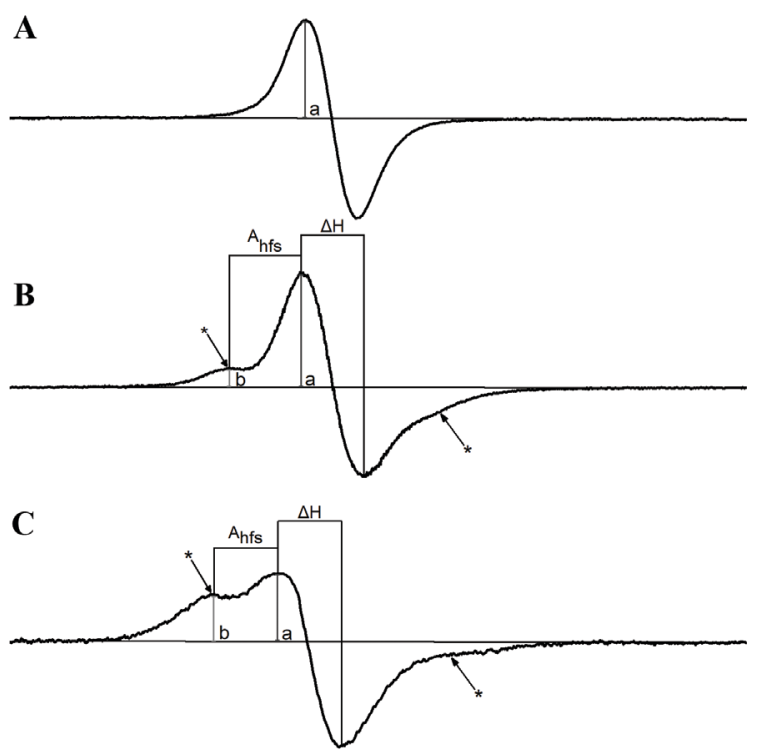

D

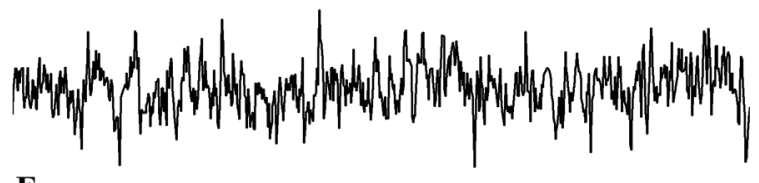

$\mathbf{E}$

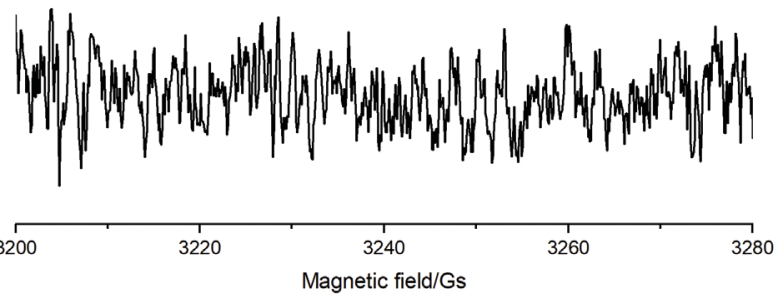

Figure 4. Representative EPR spectra of analyzed materials:

A - synthesized eumelanin, B - studied fungus mycelium, C - synthesized melanin copolymer, D - supernatant without addition of zinc (II) acetate, $\mathbf{E}$ - supernatant with addition of zinc (II) acetate. ' $a$ ' - intensity of superpositioned bands characteristic for eu- and pheomelanin, ' $b$ '- intensity of the low-field pheomelanin band, '*' - high- and low-field bands characteristic for pheomelanin (the high-field line is poorly resolved), Ahfs - hyperfine splitting constant. $\Delta \mathrm{H}$ - linewidth of the EPR signal

The EPR measurements were performed with a Varian E-3 X-band spectrometer (Sunnyvale, LA, USA) at $77 \mathrm{~K}\left(-196^{\circ} \mathrm{C}\right)$. Initially, technical parameters were tested to obtain the spectrum of the best quality, with the lowest values of the gain and power, which may cause signal distortion. The final, established parameters for fungal mycelium analysis were as follows: modulation amplitude $1.0 \mathrm{Gs}$, receiver gain 50000 , microwave power $1 \mathrm{~mW}$, time of one scan $200 \mathrm{~s}$, time constant $0.1 \mathrm{~s}$, number of scans 3 and were then averaged.

Spectra were analyzed by calculating the ' $a$ ' and 'b' parameters, and the hyperfine splitting constant $A_{h f s}$ (which is the distance between the centers of the bands a and b). The 'a' parameter is the intensity of the band which is a linear combination (superposition) of bands of euand pheomelanin; the 'b' parameter is characteristic for pheomelanin (Sealy et al., 1982a, b). To analyze the relative proportions between eu- and pheomelanin, the $\mathrm{a} / \mathrm{b}$ 
ratio was calculated. Additionally, the $\Delta \mathrm{H}$ parameter was calculated as a linewidth of the EPR signal connected to the 'a' band. The final values of $A_{h f s}, a / b$ ratio and $\Delta H$ were the means of values calculated from 5 spectra (values of standard deviation and standard error were calculated and the second one was presented as the measurement of uncertainty in the text). Spectra were obtained from separate colonies, cultured for 21 days under the same conditions, and of comparable diameter $(5 \mathrm{~cm})$.

The calculated parameters were compared to the values obtained from a synthetic eumelanin/pheomelanin copolymer (predicted composition: $90 \%$ of pheomelanin, 10\% of eumelanin) (Fig. 4C). The spectrum of synthetic eumelanin (i.e. DOPA melanin) was also shown (Fig. 4A). Synthetic melanins were prepared based on the protocols by d'Ischia et al. (2013).

Analysis of pigment from the liquid medium. 30 days old mycelium from liquid culture was separated from the medium by centrifugation (1 h, $9600 \mathrm{rpm})$ and the supernatant was transferred into a Falcon tube. A portion of the supernatant was divided into two parts, and two specimens were prepared: $1 \mathrm{ml}$ of supernatant without any additions and $1 \mathrm{ml}$ of supernatant with an addition of $1 \mathrm{ml}$ of $100 \mathrm{mM} \mathrm{Zn}\left(\mathrm{CH}_{3} \mathrm{COO}\right)_{2} \times 2 \mathrm{H}_{2} \mathrm{O}$ solution (to increase melanin bands resolution: Sarna \& Lukiewicz, 1972; Felix et al., 1978); glass tubes, such as the one described earlier were used to prepare the samples. Frozen samples were then measured as presented earlier, except of the receiver gain - 620000 .

\section{RESULTS AND DISCUSSION}

\section{Fungus identification}

Identification by ITS sequencing of the selected isolate (GenBank accession no. MT651609) resulted in Plenodomus biglobosus (Leptosphaeria biglobosa) (Shoemaker \& Brun, 2001; de Gruyter et al., 2013) with 100\% matches with sequences in the employed databases. However, the current species concept of L. biglobosa is broadly defined with six distinct subclades, thus its systematic allocation and characterization may be re-described in the future (de Gruyter et al., 2013). In this paper, $P$. biglobosus was for the first time identified as an endophyte and saprotroph of the European ash. Ibrahim et al. (2017) previously characterized this species as a Fraxinus ornus endophyte. On the other hand, P. biglobosus was also described as one of etiological factors of phoma stem canker of oilseed rape (Brassica napus L. var. napus) (Stonard et al., 2010). Oilseed rape is an important oleaginous plant, and the mentioned disease is one of the major causes of loss of winter oilseed rape crops in Europe, Australia and North America (Fitt et al., 2006). It is worth noting that Polish strains of $P$. biglobosus are considered to be more pathogenic than strains from France, Canada or Germany, due to their production of polanrazines and phomapyrones (Stonard et al., 2010).

The cultures of $P$. biglobosus were blackening with time (Fig. 3), suggesting that they were generating and accumulating a dark pigment, most probably melanin. It is known that on oilseed rape, P. biglobosus often cooccurs with Leptosphaeria maculans (Stonard et al., 2010), which does not produce blackish pigments (Lob et al., 2013). However, there are articles in which L. maculans was described as a melanized fungus, therefore $P$. biglobosus could have been incorrectly described as L. maculans (Shoemaker \& Brun, 2001). The authors also used term
Table 1. Mean values of EPR spectra parameters calculated for fungal mycelium $(n=5)$.

$' a / b$ ' - ratio of intensity of the band ' $a$ ' (superposition of eu- and pheomelanin bands) and ' $b$ ' (characteristic for pheomelanin), Ahfs - hyperfine splitting constant - distance between ' $a$ ' and ' $b$ ' bands, $\triangle \mathrm{H}$ - linewidth of the EPR signal connected to 'a' band, S.D. - standard deviation, S.E. - standard error

\begin{tabular}{llll}
\hline Parameter & Calculated mean value & \pm S.D. & \pm S.E. \\
\hline a/b ratio & 6.0 & 0.3 & 0.1 \\
\hdashline Ahfs $/ G s$ & 7.9 & 0.2 & 0.1 \\
\hline$\Delta \mathrm{H} / \mathrm{Gs}$ & 6.6 & 0.3 & 0.1 \\
\hline
\end{tabular}

'melanin', but there were no citations or evidences that the pigment was melanin indeed, and not another pigment (Jędryczka et al., 1998; Jedryczka et al., 2002). Other authors determined P. biglobosus as Leptosphaeria maculans or Leptosphaeria maculans/Phoma lingam, and described sulphur-containing chemical species which were considered only as shunt metabolites connected to DHN-melanins synthesis pathways (Pedras \& Yu, 2009a, b).

The authors claimed in these papers that they described for the first time sulphur-containing variations of DHN-related allomelanins. However, they did not support their discoveries with EPR measurements and little is known on the pheomelanin-like DHN melanins. Nevertheless, the work of these authors opened up a new field of melanin research.

In the work presented here we finally confirm by using EPR that the pigment produced by P. biglobosus is melanin, and in particular - pheomelanin.

\section{EPR analysis of $P$. biglobosus}

EPR analysis of the fungal mycelium revealed a strong EPR signal around $g=2.004$, typical of melanin (Commoner et al., 1954). Analysis of the spectrum (Fig. 4B) revealed a hyperfine splitting of the signal with $A_{h f s}$ ca 7.5 (Table 1) suggesting that P. biglobosus produced pheomelanin (Sealy et al., 1982a, b), which is a rare type of melanins found in fungi. The splitting is a result of magnetic interaction of the unpaired electron with the magnetic nucleus of nearby ${ }^{14} \mathrm{~N}$. The third, high-field component of the splitting is usually poorly resolved (Sealy et al., 1982a; Sealy et al., 1982b). Some authors mentioned a possibility of pheomelanin being produced by fungi (Eisenman \& Casadevall, 2012; Nosanchuk et al., 2015), but few papers showing EPR analysis of fungi containing pheomelanin pigment can be found. Well-defined EPR spectra of fungal pheomelanin were published e.g. for Cladosporium cladosporioides (Buszman et al., 2006), Cladosporium sphaerospermum (Dadachova et al., 2007) and Cladosporium herbarum (Zdybel et al., 2009). Pheomelanin is also known to have a stronger prooxidant activity than other melanins (Tanaka et al., 2018). As P. biglobosus maintains this type of pigment, it must be suggested that its production is somehow evolutionarily advantageous for this species.

In the studied fungus the calculated $\mathrm{a} / \mathrm{b}$ ratio was estimated to be $6.0 \pm 0.1$ (Table 1). For a more detailed analysis of the fungal melanin spectrum, it was compared to a synthetic melanin spectrum (Fig. 4C) which was obtained from analysis of a copolymer predicted to contain $90 \%$ of pheomelanin and $10 \%$ of eumelanin. The calculated ratio of $\mathrm{a} / \mathrm{b}$ parameters was 1.4 , which stays in a good agreement with the predicted value for pure synthetic pheomelanin (1.2 \pm 0.1 , Sealy et al., 1982a) and suggests that the spectrum of $P$. biglobosus also contains a copolymer of melanins with quite a substantial par- 
ticipation of pheomelanin. For comparison, for common animal pheomelanotic materials, the $a / b$ value equals e.g. 3.5-4 for yellow $A^{\mathrm{y}} / \mathrm{a}$ mice, up to approx. 9 for an agouti phenotype (Slominski et al., 2005b; WolnickaGlubisz et al., 2013). Another typical EPR parameter the linewidth $(\Delta \mathrm{H})$ 6.6 $\pm 0.1 \mathrm{Gs}$ (Table 1) was also comparable to pheomelanin, as revealing a wider signal than eumelanin (ca. 3.5 - 4 Gs, e.g. Slominski et al., 2005a; Wolnicka-Głubisz et al., 2013).

The Ahfs (Fig. 4B) calculated for fungal mycelium was 7.9 $\pm 0.1 \mathrm{Gs}$ (Table 1), which was slightly higher than the parameter calculated for synthetic pheomelanin $\left(\mathrm{A}_{\mathrm{hfs}}=\right.$ 7.1 Gs, Fig. 4C). According to the literature, the value for synthetic pheomelanin should vary in the range of 7-7.4 Gs, but it is strongly dependent on the microenvironment of the sample, especially $\mathrm{pH}$ (Sealy et al., $1982 \mathrm{~b})$. This may be the reason of the discrepancy between our result and values found in the literature. This discrepancy remains within the frame of experimental errors but at the same time it suggests taking a closer look into the structure of the fungal pheomelanin in the future. In particular, the abovementioned suggestion on the potential structure of mers of sulphur-containing DHN-derived melanin (Pedras \& Yu, 2009a, b) should be seriously taken into consideration.

The deep-dark, almost black color of the culture (Fig. 3) may seem incongruent with the popular view that pheomelanins give 'yellow-red' coloration of biological materials, but this may be due to a purely optical phenomenon, as some samples of dried pheomelanin seem to be apparently black, and only after dissolving or spreading on a white background as a thin layer, they reveal a reddish tint (Wolnicka-Głubisz et al., 2012). Due to the high specificity of EPR parameters, our analysis revealed beyond any doubt that pheomelanin or a similar pigment with analogical structure of paramagnetic centers is produced by the mycelium of P. biglobosus.

EPR analysis of the supernatant from the liquid culture showed that melanin was not secreted outside the fungal cell. The dark color of liquid was probably caused by secretion of melanin precursors or might also result from secretion of other colored metabolites. It is possible that monomers with conjugated systems of double bonds were colored, but before polymerization they were not paramagnetic, thus, an EPR signal was not detected (Fig. 4D) even with zinc (II) acetate addition (Fig. 4E).

\section{Role of the pigment - suggestions}

Increasing intensity of the dark color of the mycelium indicates that the fungus is accumulating melanin pigments during growth and aging. Melanins, especially eumelanin, play a role as photoprotectants able to absorb and dissipate electromagnetic radiation (Kollias et al., 1991). Analyses conducted by Drewnowska and others (Drewnowska et al., 2015) showed that production of eumelanin-like pigments among bacterial strains of Bacillus weihenstephanensis differed, and the main differentiating factor was exposure to light. However, according to our observations, the pheomelanin-like pigment accumulation was present when $P$. biglobosus cultures were not exposed to light. This suggests that the role of pheomelanin in the fungus is different than the role of eumelanin in the mentioned bacteria. As pheomelanin can be phototoxic (Ito et al., 2018), this observation seems logical, but it does not explain what is the reason for generating pheomelanin in the dark. It would be also interesting to check if allo-, or eumelanin content is growing during exposure to light. Riley (Riley, 1992) suggested that initially melanin might have been a 'dustbin' for the excess of toxic orthoquinones, free radicals and metals (and maybe thiols, too), while Ito (Ito, 2003) emphasized a possibility that during biological melanogenesis initially pheomelanin is always produced, up to the exhaustion of the cellular thiol donors, and the eu/pheomelanin composition would depend on the availability of intracellular cysteine. To examine the role and production kinetics of melanin pigments in $P$. biglobosus further experiments are planned.

Pigmentation of $P$. biglobosus was already noticed by Lob and others (Lob et al., 2013), but no information on the pigment type was available. We provide the first data showing that not only eu-, or allomelanins but also pheomelanins occur in the $P$. biglobosus mycelium (Fig. 4). Besides photoprotection, another probable role of melanin in this species is its contribution to virulence. In numerous pathogens of plants, fungal melanin has been documented as a factor facilitating penetration of the host tissues and protecting the fungus against the host defense mechanisms (Płonka \& Grabacka, 2006; Taborda et al., 2008).

Nevertheless, a possible involvement of melanin in the phoma stem canker etiology (see above) remains to be shown. It is also possible that melanin is just a side product of enzymes (such as polyketide synthases) whose primary role is different (e.g. detoxication) or still unknown (Yu et al., 2015). Such studies demand a thorough and painstaking analysis at the level of molecular genetics and engineering (Takano et al., 1997, Yu et al., 2015).

The melanin pigment is probably not being secreted into the plant tissues, but nevertheless comes into their close contact. On the other hand, no pathogenic effect of P. biglobosus was observed in F. ornus (Ibrahim et al., 2017). Similarly, in our study, living leaves of F. excelsior from which the fungus was isolated, were free of visible symptoms of disease. Nevertheless, some apathogenic endophytes may become virulent under certain environmental conditions or due to accumulation of mutations (Sieber, 2007). For this reason, further studies of the significance of $P$. biglobosus melanins for the host-parasite interaction involving Fraxinus spp., as well as oilseed rape, are necessary.

\section{SUMMARY}

We isolated and identified a fungal endophyte of the European ash as Plenodomus biglobosus (Leptosphaeria biglobosa). This ascomycete, which is a pathogen of Brassicaceae and an endophyte of $F$. ornus, is shown to colonize the living and dead leaves of F. excelsior. Pronounced darkening during colony development encouraged us to analyze the pigments of $P$. biglobosus. Our study provides the first EPR analysis of melanins produced by $P$. biglobosus. This fungus synthesizes significant amounts of pheomelanin, which is rarely found in fungi. However, the actual role of this metabolite in pathogenicity, stress resistance or interactions with other microorganisms still needs to be investigated.

\section{Acknowledgements}

The authors report no conflict of interest to disclose, concerning this paper.

The authors are grateful to M.Sc. Dariusz Szczygieł for his support and advice during fungal mycelium EPR measurements. 


\section{REFERENCES}

Ali SA, Naaz I (2018) Biochemical aspects of mammalian melanocytes and the emerging role of melanocyte stem cells in dermatological therapies. Int J Health Sci 12: 69-76

Altschul SF, Gish W, Miller W, Myers EW, Lipman DJ (1990) Basic local alignment search tool. J Mol Biol 215: 403-410. https://doi. org/10.1016/S0022-2836(05)80360-2

Baral HO, Queloz V, Hosoya T (2014) Hymenoscyphus fraxineus, the correct scientific name for the fungus causing ash dieback in Europe. IMA Fungus 5: 79-80. https://doi.org/10.5598/imafungus.2014.05.01.09

Barek H, Sugumaran M, Ito S, Wakamatsu K (2018) Insect cuticular melanins are distinctly different from those of mammalian epidermal melanins. Pigment Cell Melanoma Res 31: 384-392. https://doi. org/10.1111/pcmr.12672

Bolognese F, Scanferla C, Caruso E, Orlandi VT (2019) Bacterial melanin production by heterologous expression of 4-hydroxyphenylpyruvate dioxygenase from Pseudomonas aeruginosa. Int J Biol Macromol 133: 1072-1080. https://doi.org/10.1016/i.ijbiomac.2019.04.061

Buszman E, Pilawa B, Zdybel M, Wilczyński S, Gondzik A, Witoszyńska T, Wilczok T (2006) EPR examination of $\mathrm{Zn}^{2+}$ and $\mathrm{Cu}^{2+}$ binding by pigmented soil fungi Cladosporium cladosporioides. Sci Total Environ 15: 195-205. https://doi.org/10.1016/j.scitotenv.2005.05.028

Chikvaidze EN, Partskhaladze TM, Gogoladze TV (2014) Electron spin resonance (ESR/EPR) of free radicals observed in human red hair: a new, simple empirical method of determination of pheomelanin/eumelanin ratio in hair. Magn Reson Chem 52: 377-382. https:// doi.org/10.1002/mrc.4075

Commoner B, Townsend J, Pake G (1954) Free radicals in biological materials. Nature 174: 689-691. https://doi.org/10.1038/174689a0

Dadachova E, Bryan RA, Huang X, Moadel T, Schweitzer AD, Aisen P, Nosanchuk JD, Casadevall A (2007) Ionizing radiation changes the electronic properties of melanin and enhances the growth of melanized fungi. PLOS ONE 2: e457. https://doi:10.1371/journal. pone. 0000457

Dadachova E, Casadevall A (2008) Ionizing radiation: how fungi cope, adapt, and exploit with the help of melanin. Curr Opin Microbiol 11: 525-531. https://doi.org/10.1016/j.mib.2008.09.013

De Cássia R Goncalves R, Pombeiro-Sponchiado SR (2005) Antioxidant activity of the melanin pigment extracted from Aspergillus nidulans. Biol Pharm Bull 28: 1129-1131. https://doi.org/10.1248/ bpb.28.1129

de Gruyter J, Woudenberg JH, Aveskamp MM, Verkley GJ, Groenewald JZ, Crous PW (2013) Redisposition of phoma-like anamorphs in Pleosporales. Stud Mycol 75: 1-36. https://doi.org/10.3114/ sim0004

d'Ischia M, Wakamatsu K, Napolitano A, Briganti S, Garcia-Borron JC, Kovacs D, Meredith P, Pezzella A, Picardo M, Sarna T, Simon JD, Ito S (2013) Melanins and melanogenesis: methods, standards, protocols. Pigment Cell Melanoma Res 26: 616-33. https://doi. org/10.1111/pcmr.12121

Drewnowska JM, Zambrzycka M, Kalska-Szostko B, Fiedoruk K, Swiecicka I (2015) Melanin-Like Pigment Synthesis by Soil Bacillus weihenstephanensis Isolates from Northeastern Poland. PLoS One 10: e0125428. https://doi.org/10.1371/journal.pone.0125428

Eisenman HC, Casadevall, A (2012) Synthesis and assembly of fungal melanin. Appl Microbiol Biotechnol 93: 931-940. https://doi. org/10.1007/s00253-011-3777-2

El-Bialy HA, El-Gamal MS, Elsayed MA, Saudi HA, Khalifa MA (2019) Microbial melanin physiology under stress conditions and gamma radiation protection studies. Radiat Phys Chem 162: 178-186. https://doi.org/10.1016/i.radphyschem.2019.05.002

Felix CC, Hyde JS, Sarna T, Sealy RC (1978) Interactions of melanin with metal ions. Electron spin resonance evidence for chelate complexes of metal ions with free radicals. I Amer Chem Soc 100: 39223926. https://doi.org/10.1021/ja00480a044

Fitt BDL, Brun H, Barbetti MJ, Rimmer SR (2006) World-wide importance of phoma stem canker (Leptosphaeria maculans and L. biglobosa) on oilseed rape (Brassica napus). Eur J Plant Pathol 114: 3-15. https:// doi.org/10.1007/s10658-005-2233-5

Fogarty RV, Tobin JM (1996) Fungal melanins and their interactions with metals. Ensyme Microb Technol 19: 311-317. https://doi. org/10.1016/0141-0229(96)00002-6

Gardes M, Bruns TD (1993) ITS primers with enhanced specificity for basidiomycetes - application to the identification of mycorrhizae and rusts. Mol Ecol 2: 113-118. https://doi.org/10.1111/j.1365294X.1993.tb00005.x

Godechal Q, Gallez B (2011) The Contribution of electron paramagnetic resonance to melanoma research. I Skin Cancer 2011: 1-6. https://doi.org/10.1155/2011/273280

Gross A, Holdenrieder O, Pautasso M, Queloz V, Sieber TN (2014) Hymenoscyphus pseudoalbidus, the causal agent of European ash dieback. Mol Plant Pathol 15: 5-21. https://doi.org/10.1111/mpp.12073
Hines HM, Witkowski P, Wilson JS, Wakamatsu K (2017) Melanic variation underlies aposematic color variation in two hymenopteran mimicry systems. PLOS ONE 12: e0182135. https://doi. org/10.1371/journal.pone.0182135

Ibrahim M, Sieber TN, Schlegel M (2017) Communities of fungal endophytes in leaves of Fraxinus ornus are highly diverse. Fungal Ecol 29: 10-19. https://doi.org/10.1016/j.funeco.2017.05.001

Ito S (2003) The IFPCS presidential lecture: a chemist's view of melanogenesis. Pigment Cell Res 16: 230-236. https://doi:10.1034/j.16000749.2003.00037.x

Ito S, Wakamatsu A, Sarna T (2018) Invited review photodegradation of eumelanin and pheomelanin and its pathophysiological implications. Photochem Photobiol 94: 409-420. https://doi.org/10.1111/ php. 12837

Jędryczka M, Lewartowska E, Plachka E, Ziman L (1998) Studies on the populations of the fungus Leptosphaeria maculans in Moravia and western Slovakia. Rośliny oleiste 19: 473 - 483

Jedryczka M, Nikonorenkov VA, Gasich E, Lewartowska E, Portenko L, Levitin M (2002) Spectrum and severity of fungal diseases on spring oilseed rape in Russia. IOBC Bulletin 25: 13-20

Kaney AR, Knox GW (1980) Production of melanin precursors by a mutant of Tetrabymena thermophila. J Protozool 27: 339-341. https:// doi.org/10.1111/j.1550-7408.1980.tb04274.x

Karlsson O, Berg C, Brittebo EB, Lindquist NG (2009) Retention of the cyanobacterial neurotoxin beta- $N$-methylamino-l-alanine in melanin and neuromelanin-containing cells - a possible link between Parkinson-dementia complex and pigmentary retinopathy. Pigment Cell Melanoma Res 22(1): 120-130. https://doi.org/0.1111/j.1755148x.2008.00508.x

Kelley JL, Rodgers GM, Morrell LJ (2016) Conflict between background matching and social signalling in a colour-changing freshwater fish. R Soc Open Sci 3: 160040. https://doi.org/10.1098/ rsos. 160040

Kollias N, Sayre RM, Zeise L, Chedekel M R (1991) Photoprotection by melanin. J Photochem Photobiol B 9: 135-160. https://doi. org/10.1016/1011-1344(91)80147-a

Kowalski T (2006) Chalara fraxinea sp. nov. associated with dieback of ash (Fraxinus excelsior) in Poland. Forest Pathol 36: 264-70. https:// doi.org/10.1111/j.1439-0329.2006.00453.x

Land EJ, Ramsden CA, Riley PA (2004) Quinone chemistry and melanogenesis. Methods Enzymol 378: 88-109. https://doi.org/10.1016/ S0076-6879(04)78005-2

Lob S, Jaspers MV, Ridgway HJ, Jones EE (2013) First report of Leptosphaeria biglobosa as a stem canker pathogen of Brassicas in New Zealand. Plant Dis 97: 1113. https://doi.org/10.1094/PDIS-12-121122-PDN

Martin Gonzalez A, Benitez L, Soto T, Rodriguez de Lecea J, Gutierez JV (1997) A rapid bioassay to detect mycotoxins using a melanin precursor overproducer mutant of the ciliate Tetrabymena thermophila. Cell Biol Int 21: 213-216. https://doi.org/10.1006/cbir.1997.0134

Micillo R, Panzella L, Kenzo K, Monfrecola G, Napolitano A, d'Ischia M (2016) 'Fifty Shades' of black and red or how carboxyl groups fine tune eumelanin and pheomelanin properties. Int. J Mol Sci 7: 746. https://doi.org/10.3390/ijms17050746

Nilsson RH, Larsson K-H, Taylor AFS, Bengtsson-Palme J, Jeppesen TS, Schigel D, Kennedy P, Picard K, Glöckner FO, Tedersoo L, Saar I, Kõljalg U, Abarenkov K (2019) The UNITE database for molecular identification of fungi: handling dark taxa and parallel taxonomic classifications. Nucleic Acids Res 47: D259-D264. https:// doi.org/10.1093/nar/gky1022

Nosanchuk J D, Stark R E, Casadevall A (2015) Fungal melanin: what do we know about structure? Front Microbiol 6: 1463. https://doi. org/10.3389/fmicb.2015.01463

Pedras MS, Yu Y (2009a) Phytotoxins, elicitors and other secondary metabolites from phytopathogenic "blackleg" fungi: structure, phytotoxicity and biosynthesis. Nat Prod Commun 4: 1291-1304

Pedras MS, Yu Y (2009b) Salt stress induces production of melanin related metabolites in the phytopathogenic fungus Leptosphaeria maculans. Nat Prod Commun 4: 53-58

Płonka PM, Grabacka M (2006) Melanin synthesis in microorganisms - biotechnological and medical aspects. Acta Biochim Pol 53: 429-43. https://doi.org/10.18388/abp.2006_3314

Płonka PM, Rakoczy L (1997) The electron paramagnetic resonance signals of the acellular slime mould Physarum nudum plasmodia irradiated with white light. Curr Top Biophys 21: 83-86

Polak A (1990) Melanin as a virulence factor in pathogenic fungi. Mycoses 33: 215-224. https://doi.org/10.1111/myc.1990.33.5.215

Polo-Cavia N, Gomez-Mestre I (2017) Pigmentation plasticity enhances crypsis in larval newts: associated metabolic cost and background choice behaviour. Sci Rep 7: 39739. https://doi.org/10.1038/ srep39739

Pusztahelyi T, Holb IJ and Pócsi I (2015) Secondary metabolites in fungus-plant interactions. Front Plant Sci 6: 573, https://doi. org/10.3389/fpls.2015.00573

Riley PA (1992) Materia Melanica: Further Dark Thoughts. Pigment Cell Res 5: 101-106. https://doi.org/10.1111/j.1600-0749.1992.tb00005.x 
Sarna T, Lukiewicz S (1972) Electron spin resonance on living cells. IV. Pathological changes in amphibian eggs and embryos. Folia Histochem Cytochem 10: 265-278

Sealy RC, Hyde JS, Felix CC, Menon IA, Prota G (1982a) Eumelanins and pheomelanins: characterization by electron spin resonance spectroscopy. Science 217: 545-547. https://doi.org/10.1126/science.6283638

Sealy RC, Hyde JS, Felix CC, Menon IA, Prota G, Swartz HM, Persad S, Haberman HF (1982b) Novel free radicals in synthetic and natural pheomelanins: distinction between dopa melanins and cysteinyldopa melanins by ESR spectroscopy. Proc Natl Acad Sci US A 79: 2885-2889. https://doi.org/10.1073/pnas.79.9.2885

Shoemaker RA, Brun H (2001). The teleomorph of the weakly aggressive segregate of Leptosphaeria maculans. Can J Bot 79: 412-419. https://doi.org/10.1139/cjb-79-4-412

Shoeva OY, Mursalimov SR, Gracheva NV, Glagoleva AY, Börner A, Khlestkina EK (2020) Melanin formation in barley grain occurs within plastids of pericarp and husk cells. Sci Rep 10. https://doi. org/10.1038/s41598-019-56982-y

Sieber TN (2007) Endophytic fungi in forest trees: are they mutualists?. Fungal Biol Rev 21: 75-89. https://doi.org/10.1016/j.fbr.2007.05.004

Slominski A, Płonka PM, Pisarchik A, Smart JL, Tolle V, Wortsman J, Low MJ (2005a) Preservation of eumelanin hair pigmentation in proopiomelanocortin-deficient mice on a nonagouti (a/a) genetic background. Endocrinology 146: 1245-1253. https://doi.org/10.1210/ en.2004-0733

Slominski A, Tobin DJ, Shibahara S, Wortsman J (2004) Melanin pigmentation in mammalian skin and its hormonal regulation. Physiol Rev 84: 1155-228. https://doi.org/10.1152/physrev.00044.2003

Slominski A, Wortsman J, Płonka PM, Schallreuter KU, Paus R, Tobin DJ (2005b) Hair Follicle Pigmentation. I Invest Dermatol 124: 13-21. https://doi.org/10.1111/j.0022- 202x.2004.23528.x

Stonard JF, Latunde-Dada AO, Huang YJ, West JS, Evans N, Fitt BDL (2010) Geographic variation in severity of phoma stem canker and Leptosphaeria maculans/ L. biglobosa populations on UK winter oilseed rape (Brassica napus). Eur J Plant Pathol 126: 97-109. https:// doi.org/10.1007/s10658-009-9525-0

Suwannarach N, Kumla J, Watanabe B, Matsui K, Lumyong S (2019) Characterization of melanin and optimal conditions for pigment production by an endophytic fungus, Spissiomyces endophytica SDBRCMU319. PLOS ONE 14(9): e0222187. https://doi.org/10.1371/ journal.pone.0222187

Taborda CP, da Silva MB, Nosanchuk JD, Travassos LR (2008) Melanin as a virulence factor of Paracoccidioides brasiliensis and other dimorphic pathogenic fungi: a minireview. Mycopathologia 165: 331339. https://doi.org/10.1007/s11046-007-9061-4

Takano Y, Kubo Y, Kawamura C, Tsuge T, Furusawa I (1997) The Alternaria alternata Melanin biosynthesis gene restores appressorial melanization and penetration of cellulose membranes in the melanin-deficient albino mutant of Colletotrichum lagenarium. Fungal Genet Biol 21: 131-140. https://doi.org/10.1006/fgbi.1997.0963
Tanaka H, Yamashita Y, Umezawa K, Hirobe T, Ito S, Wakamatsu K (2018) The pro-oxidant activity of pheomelanin is significantly enhanced by UVA irradiation: benzothiazole moieties are more reactive than benzothiazine moieties. Int J Mol Sci 19: 2889. https:// doi.org/10.3390/ijms1910288

Thaira H, Raval K, Manirethan V, Balakrishnan RM (2019) Melanin nano-pigments for heavy metal remediation from water. Separ $S_{c i}$ Tech 54: 265-274. https://doi.org/10.1080/01496395.2018.1443132

Varga M, Berkesi O, Darula Z, May NV, Palágyi A (2016) Structural characterization of allomelanin from black oat. Phytochemistry 130: 313-320. https://doi.org/10.1016/j.phytochem.2016.07.002

Vilgalys R, Hester M (1990) Rapid genetic identification and mapping of enzymatically amplified ribosomal DNA from several Cryptococcus species. J Bacteriol 172: 4238-46. https://doi.org/10.1128/ jb.172.8.4238-4246.1990

Wang H, Qiao Y, Chai B, Qiu C, Chen X (2015) Identification and molecular characterization of the homogentisate pathway responsible for pyomelanin production, the major melanin constituents in Aeromonas media WS. PLOS ONE 10: e0120923. https://doi. org/10.1371/journal.pone.0120923

Wang Z, Dillon J, Gaillard ER (2006) Antioxidant properties of melanin in retinal pigment epithelial cells. Photochem Photobiol 82: 474. https://doi.org/10.1562/2005-10-21-ra-725

Wolnicka-Głubisz A, Pecio A, Podkowa D, Kołodziejczyk ŁM, Płonka PM (2012) Pheomelanin in the skin of Hymenochirus boettgeri (Amphibia: Anura: Pipidae). Exp Dermatol 21: 535-56. https://doi. org/10.1111/j.1600-0625.2012.01511.x

Wolnicka-Głubisz A, Pecio A, Podkowa D, Płonka PM, Grabacka M (2013) HGF/SF Increases number of skin melanocytes but does not alter quality or quantity of follicular melanogenesis. PLOS ONE 8: e74882. https://doi.org/10.1371/journal.pone.0074883

Yu X, Huo L, Liu H, Chen L, Wang Y, Zhu X (2015) Melanin is required for the formation of the multi-cellular conidia in the endophytic fungus Pestalotiopsis microspora. Microbiol Res 179: 1-11. https:// doi.org/10.1016/j.micres.2015.06.004

Zdybel M, Pilawa B, Buszman E, Witoszyńska T, Brotoń B (2009) Paramagnetism of pigmented soil fungi Cladosporium herbarum. Nukleonike 89-91: 173-175

Zadlo A (2019) Application of transition metal ions in a study of photoinduced modifications of melanin. Acta Biochim Pol 66: 237-241. https://doi.org/10.18388/abp.2018_2802

Zadlo AC, Sarna T (2019) Interaction of iron ions with melanin. Acta Biochim Pol 66: 459-462. https://doi.org/10.18388/abp.2019_2889

Zhang P, Wang X, Fan A, Zheng Y, Liu X, Wang S, Zou $\bar{H}$, Oakley BR, Keller NP, Yin WB (2017) A cryptic pigment biosynthetic pathway uncovered by heterologous expression is essential for conidial development in Pestalotiopsis fici. Mol Microbiol 105: 469-483. https://doi.org/10.1111/mmi.13711 